\title{
Том \\ Science Communication as a design challenge in transdisciplinary collaborations
}

\section{Éva Kalmár and Hanneke H. Stenfert}

\begin{abstract}
In this series of comments, we argue for Science Communication as an enabler of transdisciplinary, integrative collaboration in the context of today's complex, multi-stakeholder issues. Participatory design, as a collaborative method, is effective in achieving mutual learning, shared understandings, integrating disciplines and creating solutions that make sense in the multi-layered reality of today's challenges. Science Communication, therefore, is communication design in transdisciplinary collaborations.
\end{abstract}

Keywords

Participation and science governance; Public engagement with science and technology; Social inclusion

https://doi.org/10.22323/2.19040301

Submitted: 14th August 2020

Accepted: 17th August 2020

Published: 1st September 2020

We live in a fascinating era. Plenty of technologies are emerging from scientific inquiry; innovations revolutionise our industry and everyday life. Science communication is and always was an essential and organic part of scientific discovery. New innovations are focusing on solving problems that have social, economic and legal perspectives at the same time. Therefore, these issues cannot be addressed only by using technological or natural scientific approaches. They are in need of e.g. social sciences and the involvement of professionals outside academia. These changing inter- and transdisciplinary ways require new forms of science communication. Following these trends, the Science Communication section of Science Communication and Education department at TU Delft has reshaped its research and education portfolio during the last years. Through this profiling process, we came up with the name Communication Design for Innovation, because it seems to reflect better what is needed from science communication professionals today.

In this series of comments, we asked professionals from different fields to share their views on and experiences in interdisciplinarity, knowledge and perspective integration, design thinking and participatory design. We shorty sum up their comments while we introduce our vision on science communication. 
Science

Communication is

(or should be) a

collaborative

discipline
The challenges of our modern world are becoming multi-dimensional, integrating not only technological but also societal, economic, health and environmental issues. The complexity of these problems requires the involvement of multiple stakeholders, actors from different organisations, interests and spheres of activity in the processes aiming to tackle these problems [National Academies of Sciences, Engineering and Medicine, 2017; van der Sanden and Flipse, 2015]. Solving these problems often requires behaviour change at a personal and at an organisational level [Brown, Harris and Russell, 2010]. Integrating multiple stakeholders is a crucial element in tackling these problems for several reasons. First of all, complex problems often require systematic change due to the interconnectedness of the spheres and sectors the issues manifest. Second, systemic changes may cause a power shift among the actors in society. Changes that affect different actors can only be sustainable if these actors are also willing to adopt the changes [Waddell et al., 2015].

Public engagement with science and technology and public participation in science are widely accepted approaches in science communication taking the societal aspects into account. These argue that instead of using one-way communication channels, scientists should actively reach out to society and engage people in discussions or even in participating in scientific activities [Stilgoe, Lock and Wilsdon, 2014]. However, it can be questioned whether these approaches are enough to address the level of involvement that is needed these days.

One of the issues stated as a critique to pubic engagement and public participation is that these, in general, put the responsibility of communicating science effectively to the individuals. Scientists are claimed to do the science, ideally, by identifying all the scientific perspectives relevant for the solution and forming transdisciplinary research teams; listen to the public and figuring out what people know, feel and think about the particular problem; design audience-specific messages; and finally evaluate these communication acts, with minimal organised institutional support [van der Sanden and Osseweijer, 2011]. All these tasks require specific expertise and skills [Fischhoff and Scheufele, 2013]. But based on the National Academies of Science report on Communicating Science Effectively, many individual scientists performing science communication tend to fail in identifying clear and feasible goals; overestimate what most people know about the subject; overrate the effectiveness of their efforts; and many of them lack the knowledge of communication theories [National Academies of Sciences, Engineering and Medicine, 2017].

In our view, instead of being a product of an individual scientist or science officer, science communication is or should be a collaborative effort between scientists with divergent relevant perspectives on the one hand; and a collaborative effort between these scientists and other professionals, such as behavioural and communication experts, science communication professionals and project managers to tackle the complex, multi-stakeholder issues effectively, on the other hand [Fischhoff, 2019; van der Sanden and Flipse, 2015].

Megan K. Halpern and Michael O'Rourke mention in their comment that collaborations developing science communication, which can be defined as communities of practice or social worlds, are rarely researched. These science communication collaborations face challenges such as managing differing sets of 
priorities, knowledges and skills, as well as a lack of formal structures by which expectations can be clarified. But the focus of this particular comment is on a hardly ever mentioned issue in these science communication collaborations: the power differences between members. They bring examples for how power differences can stand behind the unaligned goals in collaborations developing informal learning programs, and the undiscussed ways of cooperation in teams creating new science museum exhibitions. They also show how different interventions, such as the Toolbox dialogue or the Cultural probes can address these power differences and facilitate knowledge sharing among different experts in science communication communities of practice.

The need for integrative collaborative processes
Based on the quality and level of integration, one can distinguish between multidisciplinary, interdisciplinary and transdisciplinary teams [Stokols et al., 2008]. These terms are sometimes used interchangeably. For clarity, we understand teamwork which involves the integration of knowledge from two or more disciplines as interdisciplinary collaboration [Sonnenwald, 2007]. Under the term transdisciplinary collaboration, we understand two things. First, we see transdisciplinary research as an integrative process in which scientists work together to develop a shared conceptual framework that synthesises and extends discipline-specific knowledge, creating new models and language to address a common problem. Second, in transdisciplinary teams, in our understanding, the involvement of non-traditional stakeholders from other sectors of society is essential [Pohl and Hirsch Hadorn, 2008].

Renate Klaassen shows in her comment that scholars investigating teamwork crossing disciplines have different definitions and understandings about what interdisciplinarity is, which can be related to the field these experts represent. Based on the discussions during the Humboldt University's "Interdisciplinarity revisited" lecture series, Klaassen explains various distinctions scholars make regarding interdisciplinarity. She discusses the differences between wider and closer interdisciplinarity and how interdisciplinarity could be extended to include the public as well. She brings examples for the bottom-up and top-down organisation of interdisciplinarity in institutions.

The most general form of science-related teamwork is sequential interdependence. Members participating in this kind of partnership work on the same project, but they are only responsible for their parts of the project. In the end, they provide the results of these sub-projects, and the effect is more significant than any member could accomplish on its own. It mainly requires awareness and complementarity to set up and efficiently run these types of projects, so these are considered rather easy to establish [Walsh and Bayma, 1996]. Partnerships in which participants work together throughout the whole research process, from developing ideas, through carrying out research and solving occurring challenges, to summing up the results are called integrative collaborations [Hinrichs et al., 2017].

Transdisciplinary teams and their integrative collaboration have the potential to solve complex or wicked problems, as the problem definition made by the different participants can lead to a greater understanding of the problem, by respecting the individual perspectives [Brown, Harris and Russell, 2010; Norris et al., 2016]. Companies also often adopt transdisciplinary teams consisting of designers, 
managers, developers and users for efficient problem solving and decision making [Seidel and Fixson, 2013].

The current Covid-19 pandemic serves as an example to show how the science communication community sees who should be invited to the table to discuss the implications of science concerning Covid-19 mitigations. The Dutch publicist and scientist, Rosanne Hertzberger critiques in a newspaper column [Hertzberger, 2020] that only experts are allowed to talk about scientific issues. This is in line with the anti-vaccination discussion [van der Sanden and Flipse, 2016], in which people formulating critique against vaccination are not taken seriously, because they are not scientific experts. Topics important in the mutual relation between science and society, such as scientific and societal uncertainty and content- and process-wise trust are mostly left undiscussed. This narrow view on inclusion and integration involving only people who are officially knowledgeable about the topic is not useful to solve complex problems, such as the effects of the current pandemic.

Gabriele Bammer shows different options on how science communication could be an internal part of inter- and transdisciplinary research teams in her comment. She discusses that science communication experts included in inter- or transdisciplinary teams should be at least familiar with systems thinking and the best practices of collaboration; otherwise, their contribution to these teams may be minimal. She discusses that effective communication and systems thinking is required to ensure that such groups understand the artificial nature of barriers between disciplines and sectors, the dynamic nature of relationships between these stakeholders, more importantly, the differences of perspectives, and finally the need to keep the whole in mind. Communication, in her view, is not only needed for knowledge sharing within these diverse teams or to external parties but is also essential to provide an understanding of the perspectives of the various stakeholders and to make the collaboration between different stakeholders and disciplines smooth. Therefore she suggests that science communication should join the new discipline of Integration and Implementation Science.

\section{Design (thinking) to facilitate transdisciplinary collaborations}

Although the integration of different conceptual frameworks, methods and applications is essential to solving complex problems [Hinrichs et al., 2017], this process of transdisciplinary integration is not easy [Bammer et al., 2020]. It requires respect, trust and the emergence of shared understandings amongst all collaborating partners. Above all, integration requires special expertise, at the level of "knowing what" (understanding what is needed to be integrated), but also at the level of "knowing how" (using methods or interventions that support integration) [Bammer et al., 2020]. Differences in perspectives, knowledge, cultures can lead to conflicts regarding the distribution of tasks, scheduling issues, managing projects, leadership and organisation and information flow between the partners [Walsh and Bayma, 1996]. It is a to-be-acquired skill to collectively establish communications that contribute to shared understandings and actions contributing to solutions to the challenges of our world.

Taking a look at the discipline and practice of design (thinking) offers us insights into these necessary skills [de Vries and van der Sanden, 2016]. The process of design thinking is often used in inter- and transdisciplinary teams working on complex innovations. Design teams are generally multidisciplinary, consisting of 
designers, managers, developers and users. The decision making and problem-solving processes that cut through complexity within such diverse groups rely on design thinking methods, and multiple forms of communication serve as a basis to facilitate these interdisciplinary teams [Chasanidou, Gasparini and Lee, 2014].

“Design thinking allows multi-professional teams to develop a mutual understanding due to its strong emphasis on team-based learning regarding both the problem and its potential solutions. Monodisciplinary, pre-established rationales are being replaced with strategies that help to develop a common ground of knowledge and agreement between disciplines. Thus, design thinking helps team members to momentarily disregard the 'drawers' in which they have internalised in their academic training - until a problem has been defined precisely enough for professional rationales and expert knowledge to be suitably applied." [Lindberg, Noweski and Meinel, 2010].

In their comment, Elisabeth LaPensee and Aalap Doshi highlight methods based on design thinking they use at the earliest stage of interdisciplinary research teams to support team formation. They show that these methods can help the forming teams to handle ambiguity that is emerging when researchers need to go out of their disciplinary silos to generate innovative ideas with each other, particularly when the ultimate goal is 'fuzzy'. These methods which are aimed to understand 'user' needs, amplifying diversity, context setting, making things visual and so on also foster collective creativity and create engaging environments in which researchers can collaboratively navigate ambiguous conversations and rapidly reach group consensus.

Learning from participatory design projects
The field of participatory design puts design thinking in practice in collaborative processes including designers and non-designers, experts and laymen. The field, which grew up in the 60s in various parts of the world, has aimed to contribute to development, social movements and transformations in society [Blundell Jones, Petrescu and Till, 2005; Broome, 2005; Hatch, 1984; Sanders and Stappers, 2008; Sanoff, 1988].

Social learning is a key aspect in these participatory design processes [Collins and Ison, 2006]. The movement of positions or perspectives in participatory processes relies on the potential for learning, through the acquisition and sharing of knowledge, through the overcoming of misunderstanding and the creation of new ideas [Richardson and Connelly, 2005; Wenger, 2011]. It is a learning process in which various actors engage, a collaborative design process [Mayer et al., 2005; Payne, Storbacka and Frow, 2008].

During the process, knowledge about the complex nature of the design problem at hand and the best routes to take towards a design solution is gradually gathered. This is done by trying out different ways of looking at the problem, and experimenting with various solution directions until a satisfactory result has been achieved. Design can be described as a process of going through many of these learning cycles towards a designed solution [Lawson and Dorst, 2009]. 
This learning in participatory design can be defined as the process of establishing a change of understanding through social learning [van der Sanden and Wehrmann, in press]. The change of understanding can be at a surface level, for instance via the recall of new information, or at deeper levels, referring to a change in attitudes or world views [Reed et al., 2010]. This highlights that the concept of understanding is not only used to refer to cognitive aspects, but is influenced by affective aspects as well. Referring to change of understanding; it addresses understanding as 'knowing' by head, but also by heart [Calderon Salazar and Huybrechts, 2020; Akama, Light and Kamihira, 2020]. The participatory design table is a place where different perspectives and even ontologies are allowed to exist; it is a place that is able to work in a context of complexity.

Paola Alfaro-d'Alençon and Horacio Torrent Schneider share their learnings from participatory design projects in housing and urban development. The concept of co-production of commons is central in these learnings, which implies that "citizens can play an active role in the public generation of goods and services in which they are directly involved or that are of importance to them". They highlight the innovative potential of more inclusive approaches to challenge traditional spatial planning frameworks, requiring new frameworks to support co-productive initiatives.

Science

Communication as participatory communication design
Participatory design is closer to science communication than one might think [van der Sanden and Wehrmann, 2014]. For example, the motives for participatory design more or less overlap with the reasons to engage the public with science and technology. The ethical or political perspective resonates well with the ideas formulated by the democratisation of science movement: citizens have the right to influence the world they are living in, the technologies they are going to use to solve societal problems they are part of. The second perspective is focusing on assuring the quality and acceptance of the product. This can be reached by fulfilling the theoretical motive for participatory design, which is highlighting the need for multi-perspective, multi-sector and multidisciplinary teams in solving design problems for a better grip on the complex problem. The final aspect is pragmatic: by involving the users; better design specification can be achieved; actual users can tell their needs, experiences and expectations better than any prediction [Greenbaum and Halskov, 1993]. By involving potential users in the design process, the acceptance of the product or the technology itself can be increased [Ives and Olson, 1984]. This perspective is often heard in science communication debates as well [Currall et al., 2008; Hess, 2014; Byrne, 2006].

The degree of user participation in participatory design projects represent points on a continuum between no involvement and involvement by strong user control. In between these extremes, there are different levels of participation, like symbolic involvement, in which case user input is requested but ignored; user advice, which is solicited through interviews or questionnaires or the user being part of the design team [Ives and Olson, 1984]. But if we look at the participatory design projects from the perspective of the user's role, then we end up with three major categories: design for users, design with users and finally design by users [Bergvall-Kåreborn and Ståhlbrost, 2008]. Here below we explain these approaches in more detail and draw analogies with different science communication approaches. 
Design for users - science for people. In the design for users type of participatory projects, professional design teams are designing products and services for and on behalf of the users. They have general data, models, theories and specific methods (interviews, questionnaires, focus groups and ethnography) to get insights into the needs of the users. The users do not actively participate in the design process; they only have a slight influence, which can be seen as customization [Bergvall-Kåreborn and Ståhlbrost, 2008].

This is the level at which effective public engagement projects are operating. It is resonating to Irwin's notion of science for people, aiming at making science policy more responsive to people's understanding, and making science-related decision-making more democratic [Irwin, 1995].

Design with users - science by the people, citizen science projects. When products and services are co-designed by designers and users, we talk about projects that fall into the category of design with users. In these projects, usually, there are still clear distinctions between the roles and responsibilities of the designers and the users, but the role of users is much more significant. The designers have the initiator and facilitator role. The users have a strong input related to context and evaluation. The users" "main resource is their knowledge of the context, together with their vision for the system, and their main skills are cooperative. The designers are change agents supporting the users in their endeavor, ensuring that they have the opportunity to take those decisions that are important to them and making sure that they do so in an informed manner" [Bergvall-Kåreborn and Ståhlbrost, 2008].

We can see a clear parallel with Irwin's ideas about science by people, in which he made an emphasis on local and contextual knowledge of citizens, which should be taken into account in technological risks and policy debates [Irwin, 1995]. This aspect of science communication focuses on understanding the standpoints of the citizens, and even learn from them.

In our view this is also the level on which most public participation in science projects are operating, by involving citizens in scientific research with the purpose of promoting public understanding of science [Bonney, 1996]. The biggest difference between citizen science and design with users projects is that citizen science expects learning happening only at the citizen's side [Strasser et al., 2019]. This process is designed such a way that citizens get information on a specific scientific field from the experts, and in return they provide data. One of the biggest drawbacks of these projects is that the setup does not provide possibilities for scientists, science communicators to understand the citizen's perspectives, therefore excluding mutual learning during the projects. Multiple perspectives are not taken into account and the process is based on the easiest way of scientific teamwork, sequential interdependence. These projects could utilize the knowledge and expertise of professionals involved in design with users projects to facilitate mutual learning.

Design by users - radical citizen science or DIY science projects. In the design by users type of participatory design the users get even more involved, and the designers only take the role of "enhancing the users' possibilities of developing a system that meets their expectations and fulfils their needs". In these types of 
projects the users design and develop parts of the idea of the product, supported by the designers and various toolkits. This approach facilitates mutual learning, as the users learn specific skills to be able to design things, and designers need to understand the underlying phenomena, when they are taking over the ideas or prototype and finalize the design [Bergvall-Kåreborn and Ståhlbrost, 2008].

This approach reminds us of the radical citizen science projects, in which citizens are involved in deciding on which scientific problems to work or do-it-yourself (DIY) biohacking projects, in which biotechnology projects are run by non-scientists together with biologist and entrepreneurs in places outside institutionalized laboratories [Strasser et al., 2019]. The major issues with these types of extreme citizen science projects are that they are not aiming to solve complex societal problems, and, in most cases, these projects are marginalized, therefore knowledge institutions and governmental organizations are not part of the projects. Therefore, even though this type of citizen science provides possibilities for mutual learning, the scope of these projects is negligible, the majority of classical scientists and science communications are excluded from the social learning processes.

We see science communication not as a single act, but as a distributed system element in the dynamic development of science and technology. We think that science communication is embedded in the inter- and transdisciplinary teams doing science in a socially responsible way. Interactions within these teams doing and communicating science are multi-way, multi-actor, multi-level and multi-staged. Through these multi-layered interactions, mutual learning is occurring. To effectively navigate in such diverse collaborations, science communication professionals could utilise the expertise of the fields of Science of Team Science and Integration and Implementation Sciences. Design thinking has been shown to be a successful adaptive approach to cut through complexity and is already used in setting up transdisciplinary teams dealing with complex problems. As learning in the proposed groups is crucial, we recommend taking a look at the lessons learned from participatory design projects to integrate their ways of working into science communication in the context of transformative innovations.

By implementing the changes mentioned above, science communication becomes communication design, a participatory design process in inter -or transdisciplinary teams of versatile professionals, in which mutual learning reflects the intensity and therefore the quality of the interaction needed. This way, communication design is stepping beyond public engagement and even public participation, since participatory design changes mindsets instead of solely processes or products. Around the table with scientists, engineers, policy makers and design-based communication researchers, that is the heart of what we research and design for at our Communication Design for Innovation department. 
Akama, Y., Light, A. and Kamihira, T. (2020). 'Expanding participation to design with more-than-human concerns'. In: Proceedings of the $16^{\text {th }}$ Participatory Design Conference 2020 - participation(s) otherwise - volume 1. ACM, pp. 1-11. https://doi.org/10.1145/3385010.3385016.

Bammer, G., O’Rourke, M., O'Connell, D., Neuhauser, L., Midgley, G., Klein, J. T., Grigg, N. J., Gadlin, H., Elsum, I. R., Bursztyn, M., Fulton, E. A., Pohl, C., Smithson, M., Vilsmaier, U., Bergmann, M., Jaeger, J., Merkx, F., Vienni Baptista, B., Burgman, M. A., Walker, D. H., Young, J., Bradbury, H., Crawford, L., Haryanto, B., Pachanee, C.-a., Polk, M. and Richardson, G. P. (2020). 'Expertise in research integration and implementation for tackling complex problems: when is it needed, where can it be found and how can it be strengthened?' Palgrave Communications 6 (1), p. 5. https://doi.org/10.1057/s41599-019-0380-0.

Bergvall-Kåreborn, B. and Ståhlbrost, A. (2008). 'Participatory design: one step back or two steps forward?' In: Proceedings of the tenth anniversary conference on participatory design 2008, pp. 102-111.

URL: https://dl .acm.org/doi/10.5555/1795234.1795249.

Blundell Jones, P., Petrescu, D. and Till, J. (2005). 'Architecture and participation: introduction'. In: Architecture and participation. London, U.K.: Spon, pp. xiii-xvii.

Bonney, R. (1996). 'Citizen science. A lab tradition'. Living Bird: For the Study and Conservation of Birds 15 (4), pp. 7-15.

Broome, J. (2005). 'Mass housing cannot be sustained'. Architecture and participation, pp. 65-75.

Brown, V. A., Harris, J. A. and Russell, J. Y. (2010). Tackling wicked problems through the transdisciplinary imagination. U.K.: Earthscan.

Byrne, P. F. (2006). 'Safety and public acceptance of transgenic products'. Crop Science 46 (1), pp. 113-117. https : //doi.org/10.2135/cropsci2005. 0151.

Calderon Salazar, P. and Huybrechts, L. (2020). 'PD otherwise will be pluriversal (or it won't be)'. In: Proceedings of the $16^{\text {th }}$ Participatory Design Conference $2020-$ Participation(s) Otherwise - Volume 1. ACM, pp. 107-115. https://doi.org/10.1145/3385010.3385027.

Chasanidou, D., Gasparini, A. and Lee, E. (2014). 'Design thinking methods and tools for innovation in multidisciplinary teams'. In: Innovation in HCI: what can we learn from design thinking, pp. 27-30.

Collins, K. and Ison, R. (2006). ‘Dare we jump off Arnstein's ladder? Social learning as a new policy paradigm'. In: Proceedings of PATH (Participatory Approaches in Science $\mathcal{E}$ Technology) conference (Edinburgh, U.K. 4th-7th June 2006). URL: http://oro.open.ac.uk/8589/.

Currall, S. C., King, E. B., Lane, N., Madera, J. and Turner, S. (2008). 'What drives public acceptance of nanotechnology?' In: The Yearbook of Nanotechnology in Society, Volume I: Presenting Futures. Dordrecht, The Netherlands: Springer, pp. 109-116. https://doi .org/10.1007/978-1-4020-8416-4_7.

de Vries, M. J. and van der Sanden, M. C. A. (2016). 'Science and technology education and communication: seeking synergy'. In: Rotterdam, The Netherlands: SensePublishers. https://doi .org/10.1007/978-94-6300-738-2. Fischhoff, B. (2019). 'Evaluating science communication'. Proceedings of the National Academy of Sciences 116 (16), pp. 7670-7675.

https://doi.org/10.1073/pnas.1805863115. 
Fischhoff, B. and Scheufele, D. A. (2013). 'The science of science communication'. Proceedings of the National Academy of Sciences 110 (Supplement 3), pp. 14031-14032. https://doi.org/10.1073/pnas.1312080110. PMID: 23942127.

Greenbaum, J. and Halskov, K. (1993). 'PD a personal statement'. Communications of the ACM 36 (6), p. 47. https://doi.org/10.1145/153571.214816.

Hatch, C. R. (1984). The scope of social architecture. New York, NY, U.S.A.: Van Nostrand Reinhold.

Hertzberger, R. (3rd July 2020). 'Er zijn meer mensen als Maurice de Hond nodig'. nrc.nl. URL: https://www.nrc.nl/nieuws/2020/07/03/er-zijn-meer-mensenals-maurice-de-hond-nodig-a4004932.

Hess, D. J. (2014). 'Smart meters and public acceptance: comparative analysis and governance implications'. Health, Risk E Society 16 (3), pp. 243-258. https://doi.org/10.1080/13698575.2014.911821.

Hinrichs, M. M., Seager, T. P., Tracy, S. J. and Hannah, M. A. (2017). 'Innovation in the knowledge age: implications for collaborative science'. Environment Systems and Decisions 37 (2), pp. 144-155. https://doi.org/10.1007/s10669-016-9610-9.

Irwin, A. (1995). Citizen Science: a Study of People, Expertise and Sustainable Development. Oxon, U.K.: Routledge. https://doi.org/10.4324/9780203202395.

Ives, B. and Olson, M. H. (1984). 'User involvement and MIS success: a review of research'. Management Science 30 (5), pp. 586-603. https://doi.org/10.1287/mnsc.30.5.586.

Lawson, B. and Dorst, K. (2009). 'Understanding design'. In: Design expertise. New York, NY, U.S.A.: Elsevier, pp. 23-50.

Lindberg, T., Noweski, C. and Meinel, C. (2010). 'Evolving discourses on design thinking: how design cognition inspires meta-disciplinary creative collaboration'. Technoetic Arts 8 (1), pp. 31-37. https://doi.org/10.1386/tear.8.1.31/1.

Mayer, I. S., van Bueren, E. M., Bots, P. W. G., van der Voort, H. and Seijdel, R. (2005). 'Collaborative decisionmaking for sustainable urban renewal projects: a simulation-gaming approach'. Environment and Planning B: Planning and Design 32 (3), pp. 403-423. https://doi.org/10.1068/b31149.

National Academies of Sciences, Engineering and Medicine (2017). Communicating science effectively: a research agenda. URL: https://www. nap.edu/read/23674/chapter/1.

Norris, P. E., O'Rourke, M., Mayer, A. S. and Halvorsen, K. E. (2016). 'Managing the wicked problem of transdisciplinary team formation in socio-ecological systems'. Landscape and Urban Planning 154, pp. 115-122. https://doi.org/10.1016/j.landurbplan.2016.01.008.

Payne, A. F., Storbacka, K. and Frow, P. (2008). 'Managing the co-creation of value'. Journal of the Academy of Marketing Science 36 (1), pp. 83-96. https://doi.org/10.1007/s11747-007-0070-0.

Pohl, C. and Hirsch Hadorn, G. (2008). 'Methodological challenges of transdisciplinary research'. Natures Sciences Sociétés 16 (2), pp. 111-121. https://doi.org/10.1051/nss:2008035.

Reed, M. S., Evely, A. C., Cundill, G., Fazey, I., Glass, J., Laing, A., Newig, J., Parrish, B., Prell, C., Raymond, C. and Stringer, L. C. (2010). 'What is social learning?' Ecology and Society 15 (4), r1. https://doi.org/10.5751/es-03564-1504r01. 
Richardson, T. and Connelly, S. (2005). 'Reinventing public participation: planning in the age of consensus'. In: Architecture and participation. Ed. by P. Blundell Jones, D. Petrescu and J. Till. London, U.K.: Spon press.

Sanders, E. B.-N. and Stappers, P. J. (2008). 'Co-creation and the new landscapes of design'. CoDesign 4 (1), pp. 5-18. https://doi.org/10.1080/15710880701875068.

Sanoff, H. (1988). 'Participatory design in focus'. Architecture and Behavior 4, pp. 27-42.

Seidel, V. P. and Fixson, S. K. (2013). 'Adopting design thinking in novice multidisciplinary teams: the application and limits of design methods and reflexive practices'. Journal of Product Innovation Management 30, pp. 19-33. https://doi.org/10.1111/jpim.12061.

Sonnenwald, D. H. (2007). 'Scientific collaboration'. Annual Review of Information Science and Technology 41 (1), pp. 643-681. https://doi.org/10.1002/aris.2007.1440410121.

Stilgoe, J., Lock, S. J. and Wilsdon, J. (2014). 'Why should we promote public engagement with science?' Public Understanding of Science 23 (1), pp. 4-15. https://doi.org/10.1177/0963662513518154.

Stokols, D., Hall, K. L., Taylor, B. K. and Moser, R. P. (2008). 'The science of team science: overview of the field and introduction to the supplement'. American Journal of Preventive Medicine 35 (2), S77-S89.

https://doi.org/10.1016/j.amepre.2008.05.002.

Strasser, B. J., Baudry, J., Mahr, D., Sanchez, G. and Tancoigne, E. (2019). "“Citizen science"? Rethinking science and public participation'. Science $\mathcal{E}$ Technology Studies 32 (2), pp. 52-76. https://doi .org/10.23987/sts. 60425.

van der Sanden, M. C. A. and Flipse, S. M. (2015). 'A cybernetic dream: how a crisis in social sciences leads us to a Communication for Innovation-Laboratory'. JCOM 14 (01), Y01. URL: https://jcom.sissa.it/archive/14/01/JC0M_1401_2015_Y01.

- (2016). 'Science communication for uncertain science and innovation'. JCOM 15 (06), C05. https://doi.org/10.22323/2.15060305.

van der Sanden, M. C. A. and Osseweijer, P. (2011). 'Effectively embedding science communication in academia: a second paradigm shift'. In: Successful Science Communication. Telling It Like it is. Ed. by D. J. Bennett, D. J. and R. C. Jennings. Cambridge, U.K.: Cambridge University Press.

van der Sanden, M. C. A. and Wehrmann, C. (in press). 'A mind-set called design thinking'. In: Design-based concept learning in science and technology education. Ed. by I. Henze-Rietvel and M. J. de Vries. Leiden, The Netherlands: Brill Pubishers.

- (2014). 'Ontwerpen van communicatiestrategieën en -middelen'. In: Wetenschapscommunicatie, een kennisbasis. The Hague, The Netherlands: Boom Lemma uitgevers.

Waddell, S., Waddock, S., Cornell, S., Dentoni, D., McLachlan, M. and Meszoely, G. (2015). 'Large systems change: an emerging field of transformation and transitions'. Journal of Corporate Citizenship 2015 (58), pp. 5-30. https://doi.org/10.9774/gleaf.4700.2015.ju.00003.

Walsh, J. P. and Bayma, T. (1996). 'Computer networks and scientific work'. Social Studies of Science 26 (3), pp. 661-703. https://doi.org/10.1177/030631296026003006.

Wenger, E. (2011). Communities of practice: a brief introduction. URL: http://hdl . handle. net/1794/11736. 
Eva Kalmar is a molecular biologist and a science communication professional at the Delft University of Technology. She investigates collaboration processes in inter- and transdisciplinary teams of scientists, business partners and government, focusing on scientific and technological innovations. She is also involved in teaching communication and collaboration theories and social scientific research methods in the interdisciplinary Communication Design for Innovation minor and master track. E-mail: e.kalmar-1@tudelft.nl.

Hanneke H. Stenfert has a background in both Science Communication and Design, at Delft University of Technology. With her office Open Kaart, located in Rotterdam, the Netherlands, she works on the development of cities, buildings and spaces. Open Kaart specialises in cocreation: users are included in the design process. Design is used to create a dialogue between stakeholders; dialogue is used to create better design. Hanneke both practices and researches these cocreative processes. E-mail: hanneke@deopenkaart.nl.

\section{How to cite}

Kalmár, É. and Stenfert, H. H. (2020). 'Science Communication as a design challenge in transdisciplinary collaborations'. JCOM 19 (04), C01. https://doi.org/10.22323/2.19040301. 